\title{
KONSEP DAN PRAKTEK KESEHATAN BERBASIS AJARAN ISLAM
}

\author{
Abdul Hadi \\ Universitas Islam Jakarta, Indonesia \\ ahdiadhm@gmail.com
}

\begin{abstract}
Quran's Position Health is a state of complete physical, mental, spiritual and social wellbeing, which must be safeguarded not only through the maintenance of a health preserving regime at the personal/individual level, but also through the establishment of a health-protective and promoting family system and a health-protective and promoting social system. In the light of Quranic verses, present Islamic principles of health and healing. Quran's injunctions regarding Health: Fundamental Duties and Fundamental Prohibitions Islam's strategy for health and healing Prevention 1. Primary .

Tahara. Nutrition .Exercise. 2- Secondary Treatment of Diseases Mental Health, spiritual Health

Therapeutic Sociology. In Islam, health is not a separate entity but one of the essential constituents of peace, which comprise peace at the individual, family and social level. There are three tiers of society: individual, family and society. All three have equal importance and none can be sacrificed through the sword of the other. Health therefore too has to involve all the three.
\end{abstract}

Keywords: moderate, peace, physical, spritual, hygene, wellbeing

Abstrak

Alquran memandang kesehatan adalah suatu kondisi sehat secara menyeluruh, baik secara fisik, mental, spiritual, dan sosial. Hal tersebut harus terjaga tidak hanya dengan menjaga masalah kesehatan secara individu, tapi juga perlu menjaga sistem menjaga kesehatan keluarga dan menjaga sistem kesehatan masyarakat.Dalam isyarat ayat-ayat Alquran mengetengahkan prinsip-prinsip menjaga kesehatan dan penyembuhan, prinsip ini terkait dengan perintah dan larangan yang harus dipatuhi agar kesehatan tetap terjaga. Pertama terkait dengan masalah kebersihan, nutrisi, dan olah raga. Kedua terkait dengan diagnosa terhadap masalah ganguan mental, spiritual, dan terapi sosial.Dalam Islam, kesehatan bukanlah entitas yang terpisah tetapi salah satu unsur penting dalam mewujudkan kedamaian, Kesehatan individu, keluarga dan sosial sangat terkait satu sama lain, dan ketiganya harus diperlakukan dengan adil dan berkesinambungan. Tidak dibenarkan mengorbankan salah satu komponen untuk kepentingan komponen lainya, ketiganya memiliki kepentingan sama dan harus diperlakukan sesuai dengan prinsip kebutuhan dan urgensinya.

Kata Kunci: moderasi, kedamaian, fisik, spritual, kebersihan, kesejahteraan 


\section{PENDAHULUAN:}

Seringkali kita melihat makna sehat apabila seseorang secara fisik selamat dari penyakit, padahal hakekat sehat itu adalah; Apabila seluruh komponen kepribadian yang tediri dari: Fisik, psikis, spritual, sosial (Bio psycho, ritual, socio well being) dalam kondisi normal dan berfungsi sebagaimana mestinya. Untuk mewujudkan kesehatan yang komprehensif tersebut, utamanya dari komponen kejiwaan modal dasarnya adalah; meyakini sepenuh hati sifat-sifat dan perbutan Allah Yang MahaAdil, Maha Penyayang, Maha Pembalas, dan sifat sifat`sifat lain yang dikenal dengan (Asmaul Husna).

Telah menjadi keyakinan orang beriman, bahwa keyakinanya tehadap hal tersebut akan melahirkan rasa optimis, positif melihat kehidupan, tabah menghadapi tantangan, cobaan, dan seluruh persoalan seperti apapun dianggap ringan, karena jiwanya memiliki nur/ cahaya dan rasa tentram yang tidak bisa ditukar dengan nilai apapun yang lain.

Dalam fenomena modern aspek spritual diakui sebagai unsur terpenting dalam menyelesaikan problema kejiwaan, dan ritual keagamaan menjadi model therapy yang sangat efektif terutama bagi client muslim imigran Amerika dan Eropa.

Hamid Zahron menyebutkan: Agama sebagai sarana untuk mewujudkan keimanan, kedamaian, dan ketenangan jiwa. Agama menurutnya merupakan anugrah Allah demi kemaslahatan manusia agar hidupnya berjalan normal. Agama akan membawa manusia pada keimanan, dan akhlak dan amalan sholeh akan membawanya pada kesehatan mental. Agama adalah kasih sayang, keikhlasan, kebahagiaan, kedamaian, dan keselamatan. ${ }^{1}$

Menurut Ibnu Kholdun dalam Mukaddimahnya menjelaskan: Masyarakat Arab tidak memperoleh kemulian tanpa memiliki stempel agama dari kenabian, dampak besar agama sangat urgen, karena meraka memiliki krakater jelek dan sulit menghargai orang lain, berkrakter kasar, sombong, dengki dan tidak koperatif. ${ }^{2}$

Dengan energi iman jiwa manusia bisa menerima nilai-nilai yang baik meski ia harus menanggung beban, tanggung jawab, dan kesulitan. Iman sangat efektif untuk mengubah dan mengembangkan typical kepribadian manusia dalam persepsi, ideology, obsesi, prilakunya.

\footnotetext{
1 . Hamid Zahron (الصحة النفسية والعلاج النفسي) Alamul Kitab, Kairo, 2011, pg.261

2. Ibnu Kholdun (المقدمة) Alhaiat al Misriyyah Lil Kitab, Kairo, 2006, pg,519
} 
Syaikh Mohammad Abduh juga menyebutkan bahwa; Agama adalah pintu gerbang menuju perbaikan, karena etika atau moral individu dan publik dapat diperoleh dari faktor agama, bahkan kekuatan agama melebihi kekuatan akal sebagai ciri khas kemulianya. ${ }^{3}$

\section{MAKNA SEHAT DALAM ISLAM}

Pola hidup artinya kebiasaan seseorang dalam hidupnya dan berlangsung dalam waktu panjang. Dalam pola hidup seseorang aka yang berkaitan dengan pola makan, minum, tidur, kebersihan, pergaulan, dll.

Islam mengajarkan agar setiap mukmin memilih pola hidup sederhana dalam segala hal, termasuk juga dalam masalah ibadah. Dalam Islam tidak dibenarkan mencampakkan urusan dunia untuk kepentingan akhirat atau sebaliknya, karena dalam persepsi Islam ada korelasi kuat antara kehidupan dunia dan kehidupan akhirat, sejauhmana manusia berbuat baik di dunia ini niscaya akan bahagia di hari kiamat dengan mendapatkan pahala dari Allah, karenanya ada korelasi hukum dalam kehidupan antara dunia dan akhirat, bagi siapa yang sesat di dunia ini niscaya akan sesat di akhiratnya. Firman Allah:

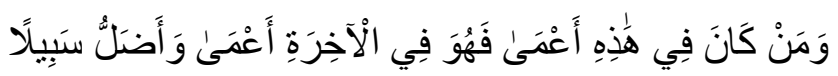

Dan barangsiapa yang buta (hatinya) di dunia ini, niscaya di akhirat (nanti) ia akan lebih buta (pula) dan lebih tersesat dari jalan (yang benar). ${ }^{4}$

Pola hidup yang baik apabila seseorang sehat secara fisik dan jiwanya, dengan memilih sifat ridho dan qonaah. Pola hidup yang baik ini akan diperoleh manusia kalau bisa mengambil jalan sedang dalam hal apapun, termasuk dalam pola makan, minum, beraktifitas, dalam pergaulan.

Setidaknya ada tiga pola menurut M. Haisyam Al-Khayyat agar manusia mempeoleh kesehatan mental ${ }^{5}$ :

1- Membiasakan hidup sehat.

2- Menghindari hal yang mudhorat atau melakukanya.

3- Kemampuan bersosialisasi dengan lingkungan

\section{A. Membiasakan Hidup Sehat.}

3 . Abdul Rozak Eid (محمد عبذه امام الحذاثة و الذستور) kutipan dari Amal Kamilah, Juz3, pg.173.

${ }^{4}$.QS. Al Isra', 72

5 . Mohammad Haisam Al Khayyat (فقه الصحة) World Health Organitation Midle East Office, Omman,1984. 
Islam memandang kesehatan itu adalah nikmat besar Allah yang diberikan pada hambaNya, karenanya rasulullah SAW bersabda:

$$
\text { نعمتان مغبون فيهما كثير من الناس: الصحة و الفراغ (رواه البخاري) }
$$

Artinya: Dua kenikmatan yang banyak dilalaikan oleh manusia yaitu: Sehat dan kesempatan. ${ }^{6}$

Kesehatan merupakan amanah Allah yang akan dinintai pertanggung jawabanya. Rasulullah SAW.bersabda: Pertanyaan Allah pertama kali adalah: Tidakkah aku berikan padamu tubuh yang sehat dan telah kuberikan air dingin untuk kesegaranya (HR. Tirmidzi). Dalam hadits lain disebutkan : Seorang hamba dihari kiamat senantiasa dalam kondisi dihisab, hingga ditanyai bagaimana ia telah habiskan usianya, dan ilmunya buat apa, hartanya dapat dari mana, dan di-Infaqkan kemana, dan fisiknya hingga binasa digunakan untuk apa? ${ }^{7}$

Banyak sekali Alqur'an dan Hadits menjelaskan tentang cara menjaga kesehatan tubuh dengan cara menjaga kebersihan tubuh keseluruhan atau satu persatu. Contoh berikut adalah cara Islam untuk menjaga kesehatan dengan kewajiban bersuci :

1) Perintah berwudhu':

Islam mewajibkan berwudhu' ketika telah batal, dan menekankan agar memperbaharuinya ketika hendak beribadah meskipun belum batal. Rasulullah SAW seperti yang diriwayatkan oleh Tirmidzhi selalu berwudhu' dalam setiap sholat, dan hukumnya sunnah bagi orang yang sedang jenabah ketika ingin makan dan minum, dan bagi suami yang ingin berhubungan intim kedua kalinya, ketika ingin tidur, sedang marah, ghibah, masuk masjid, adzhan, ziarah kubur, dan ketika menyentuh Alqur'an, jenasah, para penghafal Alquran, para pakar dalam qira'ahnya .

2) Perintah mandi

Kesehatan manusia bisa terpelihara dengan cara menjaga kebersihan tubuhnya melalui mandi setiap hari, . dan bahkan dalam Islam, bagi orang yang sedang janabah, mandi itu hukumnya wajib. Firman Allah :

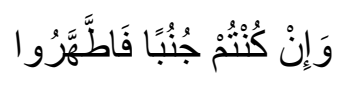

\footnotetext{
6 . Abu Hajr Mohammd Said Baisuni zaglul (موسوعة ألاطر اف الحديث النبوي الثريق) Darul Kitab Ilmiyah, volume 9, Bairut, pg. 83.

7 . Abi Isa Moammad bin Isa bin Surah (سنن الترميذي) Darul Hadits, Kairo, 2005, pg284.
} 
Dan jika kamu junub maka mandilah. ${ }^{8}$

Rasulullah SAW. menganjurkan agar mandi dalam beberapa waktu dan kondisi seperti ; hari Jum'at, Aidul fitri dan Adha, Ikhrom, setelah memandikan mayat, sebelum sholat istisqo', gerhana, I'tikaf, saat bau badan kurang enak, saat mau berkumpul dengan orang banyak.

Perintah dalam kebersihan tidak terbatas pada seluruh tubuh, tapi juga kebersihan anggota tubuh tertentu seperti perintah memcuci kedua tangan sebelum makan, memotong kuku, membersihkan kaki, mulut, dan bersiwak. Rasulullah bersabda :

$$
\text { لو لا ان أشق على أمتى لأمرتكم بالسو الك عند كل صلاة }
$$

Andaikan aku tidak mempersulit pada ummahku niscaya aku perintahkan kepada mereka untuk bersiwak dalam setiap sholat. ${ }^{9}$

Dalam hal kebersihan kedua telinga, mata, hidung, dan membersihkan rambut. Rasulullah SAW.bersabda: Bagi siapa yang memiliki rambut,seharusnya bisa memeliharanya.

Perintah membersihkan dua saluran kotoran dan alat kelamin. Daei Sitti Aisyah RA. beliau berkata: Perintahkan suamimu agar membersihkan dirinya dengan air, sebenarnya aku malu pada mereka, tapi karena Rasulullah SAW. Melakukanya, (HR. Tirmidzi). ${ }^{10}$

\section{B. Mengkonsumsi makanan yang baik:}

Untuk menjaga kesehatan wajib mengkonsumsi makanan yang baik, sedangkan yang dimaksud baik bisa ditempuh dengan cara berikut:

Pertama: Mengupayakan makanan yang bergizi dan menghindari makanan yang haram.

Kedua : Makan secukupnya, dan tidak boleh berlebihan.

Hadits Nabi Mohammad SAW:

Setiap Anak Adam tidak memenuhi sebuah bejana yang lebih jelek dari orang yang perutnya dipenuhi dengan makanan, cukuplah bagianya sejumlah makanan yang membuat tulang punggungnya menjadi kuat. ${ }^{11}$

\footnotetext{
${ }^{8}$.QS: Almaidah, 6.

9 .Abi Abdillah Mohammad bin Ismail AlBukhori (الجامع الصحيح) Darul Hadits, Suria, 1972,n/j 7239/4.

${ }^{10}$. Abi Isa Moammad bin Isa bin Surah (Ibid) pg108.

11. Abi Isa Moammad bin Isa bin Surah (Ibid) Darul Hadits. Pg 317.
} 


\section{Menghindar Dari Segala Yang Berbahaya}

Islam mengajarkan agar setiap mukmin menghindari hal yang berbahaya bagi dirinya dan berbahaya bagi orang lain. Allah melaknat orang yang berbuat modharat terhadap orang mukmin atau menipunya. Maksudnya adalah menghilangkan modharat pada individu atau klompok, dan menghindari dari hal- hal yang berbahaya baik pada individu atau kelompok.

- Modharat pada diri sendiri.

Rasulullah SAW bersabda: Tidak boleh ada kemodharatan; artinya muslim tidak boleh membiarkan dirinya terhadap bahaya penyakit dalam bentuk apapun. (HR. Tirmidzi). ${ }^{12}$

Allah mewajibkan pada muslim agar menjaga kesehatan dengan cara:

Pertama: Memberi perhatian pada hal yang bermanfaat untuk kesehatan, dengan cara mengkonsumsi makanan dan minuman yang baik dan tidak berlebihan, dan berolahraga yang cukup untuk kesehatan tubuhnya, dll.

Kedua: Menjaga diri dari hal-hal yang menimbulkan penyakit, karena tindakan preventif lebih baik dari mengobati penyakit, dan menghindari sarang yang menimbulkan penyakit, misalnya bergaul dengan orang ahli zina, dan segala jenis kejahatan lainya. Firman Allah :

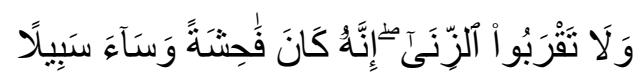

Dan janganlah kamu mendekati zina; Sesungguhnya zina itu adalah suatu perbuatan yang keji. dan suatu jalan yang buruk. ${ }^{13}$

Pengertian dosa menurut Rasyid Ridho adalah: Setiap yang berdampak negative pada diri sendiri dan materi atau berdampak negatif pada keduanya, dan dosa yang paling berat adalah membuat mudhorat dan kerugian sosial, seperti minuman keras, ganja, dan segala yang beakibat negatif pada akal manusia.

Ketiga: Setiap mukmin hendaknya berobat saat menderita penyakit, karena Rasulullah SAW. mengajarknya demikian dalam sebuah sabdanya: Berobatlah kalian, karena Allah tidak menurunkan penyakit kecuali turunkan juga obat penyembuhnya.

- Membuat mudhorat terhadap anggota keluarga:

12. Abi Isa Moammad bin Isa bin Surah (Ibid), pg. 106

13. QS: Al isra', 32. 
Yang dimaksud dengan anggota keluarga yaitu orang tua anak dan istri, haram hukumnya bagi seorang laki laki, jika tindakanya berakibat negatif pada mereka. Islam memberi nasehat agar berbuat baik pada orang tua:

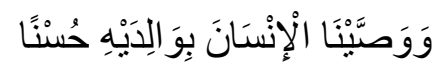

Dan kami wajibkan manusia (berbuat) kebaikan kepada dua orang ibu-bapaknya. ${ }^{14}$

Rasulullah SAW melarang tindakan yang mengakibatkan cacat pada tubuh, menyakiti orang tua, dan mengkubur hidup-hidup anak perempuan, dan bahwkan beliau berwasiat kepada para suami terhadap istrinya:

Mintalah kaliam nasehat agar baik terhadap perempuan. Dalam sabda beliau yang lain mengatakan: Ya Allah! Sesungguhya aku memudahkan hak dua hambamu yang lemah: Anak-anak Yatim dan Perempuan.

Hak mendapatkan kesehatan dan pencegahan dari penyakit bagi orang tua, istri, dan anak. Haram hukumnya jika hak mereka terabaikan, sesuai dengan Firman Allah:

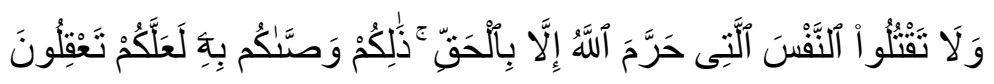

dan janganlah kamu membunuh jiwa yang diharamkan Allah (membunuhnya) melainkan dengan sesuatu (sebab) yang benar". demikian itu yang diperintahkan kepadamu supaya kamu memahami(nya). ${ }^{15}$

- Membuat modharat pada orang lain

Membuat modaharat pada orang lain teruma tetangga diharamkan dalam syara'.Rasulullah SAW.bersabda: Terlaknat orang yang bikin masalah atau menipu orang lain. Dalam hadits lain: Demi Allah tidak beriman, demi Allah tidak beriman.Sahabat bertanya; Siapa orang yang gagal dan rugi wahai Rasulullah? Rasul menjawab, Orang yang membuat tetangganya tidak aman karena kesesatan dan kejahatanya.

Membuat modharat hukmnya haram, Firman Allah :

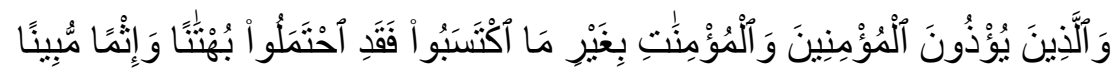

${ }^{14}$.QS: al Ankabut, 8.

15 .QS: Al An'an, 151 
Dan orang-orang yang menyakiti orang-orang yang mukmin dan mukminat tanpa kesalahan yang mereka perbuat, Maka Sesungguhnya mereka Telah memikul kebohongan dan dosa yang nyata. ${ }^{16}$

Dan rasulullah SAW. mengigatkan partisipasi setiap anggota masyarakat apapun bentuknya agar terhindar dari hal yang mengangu masyarakat, sesuai dengan sabdanya: Barang siapa berjalan menuju masjid atau pasar untuk sesuatu kebutuhan, dan ia membawa anak panah, maka ujung panah tersebut hendak dipegang atau diikat, mencegah supaya tidak mengenai siapapun dari orang-orang Islam .

\section{Kemampuan Bersosialisasi dengan lingkungan}

Rasulullah SAW bersabda: Seorang muslim yang bergaul dengan masyarakatnya dan sabar dari hal yang membuatnya tersakiti, lebih baik dari muslim yang menjauhkan dirinya dari mareka dan tidak sabar dari hal yang menyakitinya.

Bergaul dengan masyarakat menjadi prinsip paling dasar dalam menjaga kesehatan. Dalam konsep Islam bergaul dengan masyrakat hendaknya didasarkan pada empat pilar-pilar penting berikut: 1. menjaga silatur rahim, 2. tolong menolong. 3. kebutuhan pokoknya terpenuhi. 4. beramal sholeh.

\section{1- Silatur Rohim}

Dalam pemahaman Islam maksud dari istilah ini bukanlah seseorang melebur dengan masyrakat, tapi seseorang hendaknya saling mengikat satu sama lainya bagaikan sebuah bangunan yang satu sama lainya saling melengkapi. Sabda rasul dalam hadis lain menyebutkan: Perumpamaan orang mukmin dalam saling mencintai dan mengasihani bagaikan satu tubuh, jika salah satu anggota ada yang sakit, maka anggota tubuh lainya ikut merasakan dalam tidak tidur dan panas. Ungkapan dalam hadits ini menggunakan bentuk "Tafaaul" Maksudnya saling mencintai,saling mengkasihani, saling menyayangi.

Dalam Islam ada istilah "ذات البين kata Imam Qurthobi: adalah kondisi yang terjadi dalam sebuah perkumpulan. Menurut Rosyid Ridho: adalah ikatan agar berpegang erat diungkapkan dengan ذات البين. Dalam Alqur'an dan Sunnah kita diperintahkan untuk mengislahkan orang yang saling beermusuhan. Tugas islah hukumnya wajib karena kekuatan

16 .QS: Al ahzab,58. 
ummat dan keutuhanya tergantung pada sejauhmana keharmonisan kehidupan diantara mereka. ${ }^{17}$

Rasulullah SAW.bersabda: Tidakkah aku telah mengabarkan untukmu pada sebuah kedudukan yang melebihi kedudukan pahalanya sholat puasa dan sadhaqoh? Sahabat berkata: Baiklah baginda rasul! Rasulullah bersabda: Mendamaikan (ذات البين) hubungan manusia yang retak. Kemudian rasul bersabda: kerusakan dalam (ذات البين) adalah tukang pangkas agama, (HR, Abu daud). ${ }^{18}$

\section{Tolong Menolong:}

Sabda Rasul SAW: Sebaik-baiknya kalian adalah yang paling bermanfaat pada manusia. Dalam Hadits lain rasul bersabda: Manusia yang paling dicintai Allah adalah yang paling banyak memberi manfaat pada manusia lainya. Kewajiban sebagai muslim dapat bermanfaat pada saudarnya dan berusaha dengan maksimal agar bisa berbuat hal yang maslahat terhadap mereka. Islam melarang berbuat hal negative atau tidak perduli mereka, dan tidak termasuk golongan dari masyrakat Islam orang-orang yang tidak peduli pada kemaslahatan orang lain.

Rasulullah bersabda: Barang siapa tidak ada perhatian terhadap perkara orang Islam maka mereka bukan bagian dari mereka. Dalam hadits lain: Tidaklah iman seorang baik sehingga ia mencintai saudaranya seperti mencintai dirinya sendiri, (HR. Buchori). ${ }^{19}$

Dalam Islam istilah Fardu Kifayah dan tidak ditemukan dalam system lain adalah jaminan atas kelangsungan sifat tolong menolong. Mewjudkan hal yang bermanfaat pada masyrakat adalah fardhu kifayah(kewajiban kolektif) artinya jika dari beberapa anggota masyarakat ada yang melakukan maka kewajiban yang lain menjadi gugur, akan tetapi jika tidak ada satupun yang melakukan, konsekwensinya semuanya menanaggung dosanya. Karenanya setiap individu terbebani dengan fardhu kifayah sebelum orang lain, dan hendakya berlomba dalam kebaikan, sebagai implementasi dari firman Allah:

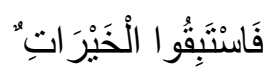

Maka berlomba-lombalah (dalam membuat) kebaikan. ${ }^{20}$

\footnotetext{
17. Sayyid Muhammad Rasyid Ridho (),pg. 117.

18 Abu Daud (سنن أبو دود) Kitab Sifatul Qiyamah wa Ar raqaiq wal wara'. Pg.218

19. Abi Abdillah Mohammad bin Ismail AlBukhori (Ibid) pg.21

${ }^{20}$.QS: Al Baqarah, 148.
} 
3. Kebutuhan dasarnya terpenuhi

Hal ini dimaksudkan bahwa masyarakat muslim hendaknya tumbuh dan berkembang,seperti digambarkan dalam Injil :

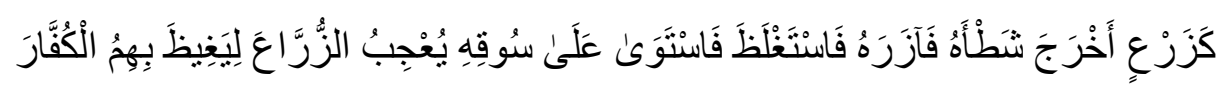

Seperti tanaman yang mengeluarkan tunasnya Maka tunas itu menjadikan tanaman itu Kuat lalu menjadi besarlah dia dan tegak lurus di atas pokoknya; tanaman itu menyenangkan hati penanam-penanamnya Karena Allah hendak menjengkelkan hati orang-orang kafir (dengan kekuatan orang-orang mukmin). ${ }^{21}$

Setiap generasi muslim hendaknya bisa seperti tunas atau cabang dari akar pohonan, tidak menjadi beban bagi masyarakatnya,akan tetapi berperan sebagai penolong dan penguat, dari aneka peran tersebut masyrakat muslim menjadi kuat dan tegak kokoh dengan prinsip agamanya yang menakjubkan.

Dasar utamanya adalah masyrakat muslim sebgai individu wajib berkonstribusi hal yang positif terhadap masyrakatnya, dan tidak menjadi beban orang lain. Setiap muslim wajib bekerja dan berusaha sendiri sehingga bermanfaat bagi dirinya dan mampu bersadekah. Dalam Islam sebagai muslim harus berusaha agar pendapatanya bisa memenuhi kebutuhanya.

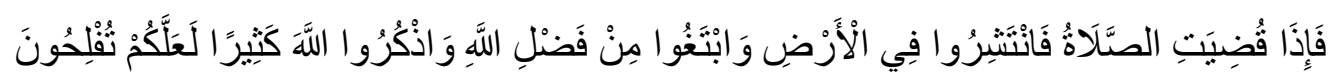

Apabila Telah ditunaikan shalat, Maka bertebaranlah kamu di muka bumi; dan carilah karunia Allah...22

Allah mendorong manusia agar bekerja sehingga dapat mendatangkan pendapatan buat dirinya,sehingga tidak meminta-minta dan berharap terhadap bantuan orang lain. Sabda Rasul SAW:

Seseorang yang mengambil tali pengikat pergi ke sebuah gunung,dan kemudian ia datang dengan ikatan kayu dipunggungnya untuk dijual dan Allah menghilangkan rasa malunya, adalah lebih baik dari orang yang meminta-minta pada orang lain, meskipun mereka memberi atau menolaknya.

${ }^{21}$.QS: Al fath,29

${ }^{22}$.QS: Al Jum'ah, 10 
Dalam hadits lain disebutkan: Tidak makan seseorng sebuah makanan yang lebih baik dari hasil keringantnya sendiri, karena Nabi Daud AS makan dari usaha sendirinya. Oleh karena itu akan tercipta masyrakat muslim yang menjadi tangan diatas bukan tangan dibawah . Dalam hal ini rasul bersabda:Tangan diatas (pemberi) lebih baik dari tangan ang dibawah(peminta), (HR. Buchori). ${ }^{23}$

\section{Beramal sholeh}

Islam meletakkan tiga pondasi untuk mebangun masyarakat Islami dalam kondisi aman dan sejahtera, tingkat keutamaanya dari pondasi ini bertingkat namun saling keterkaitan antara satu dan lainya. Pondasi dasar demi terwujudnya masyarakat islami tersebut sebagai berikut:

- Memperbaiki ikatan yang retak.

- Melakukan hal yang positif.

- Bersedekah.

Tiga hal tersebut berdasarkan pada firman Allah: Tidak ada kebaikan pada kebanyakan bisikan-bisikan mereka, kecuali bisikan-bisikan dari orang yang menyuruh (manusia) memberi sedekah, atau berbuat ma'ruf, atau mengadakan perdamaian di antara manusia.

\section{KORELASI IMAN DAN KESEHATAN}

\section{Tinjauan normatif}

Dalam Islam meyakini Arkanul imam yang enam adalah senjata yang ampuh untuk memerangi rasa putus asa, gelisah, dan negative thinking, rasa dengki, benci, dan sifat-sifat negatif lainya. Percaya pada Allah aebagai rukun pertma akan menumbuhkan keyakinan akan kekuasaan Allah SWT Yang Maha Penyembuh (الثشافي).

Memiliki kekeyakinan kuat akan efek tablet, kokin, ganja atau pengaruh obat lainya seringkali hanya mengubah alam sadar ke tidak sadar, beberapa waktu kemudian efek dari obat tersebut menjadi spot hitam di kalbu dan menimbulkan rasa gelisah, putus asa, dan amarah. Akidah yang kuat menciptakan ketentraman jiwa, ketajaman akal, menambah amunisi tubuh dari serangan penyakit. Dapat mengubah perasaan pesimis, gelisah menjadi penuh optimis dan tentram. ${ }^{24}$

\footnotetext{
23 . Abi Abdillah Mohammad bin Ismail AlBukhori (Ibid) pg.456.

24 . Abdul Hadi (البعد الديني فى الثخصيبة السوية) Maktabah Madbuli, Kairo, 2010, pg.131
} 
Dalam Alquran orang mukmin diberi anugrah hidup tentram, dan rahasia dibalik kehidupan model itu karena pengaruh iman dan takwanya. Firman Allah:

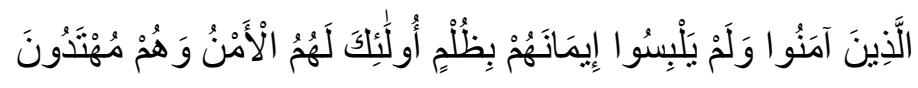

Orang-orang yang beriman dan tidak mencampuradukkan iman mereka dengan kezaliman (syirik), mereka Itulah yang mendapat keamanan dan mereka itu adalah orang-orang yang mendapat petunjuk. ${ }^{25}$

Seorang mukmin tidak akan takut terhadap hal-hal yang membuat takut bagi orang-orang pada umumnya, misalnya takut jatuh miskin, sakit, tertimpa musibah, dll, karena ia senantiasa ingat pada firman Allah:

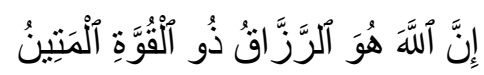

Sesungguhnya Allah dialah Maha pemberi rezki yang mempunyai kekuatan lagi sangat kokoh. ${ }^{26}$

Dan ia tidak takut fakir karena yakin Allah yang menaggung rizkinya:

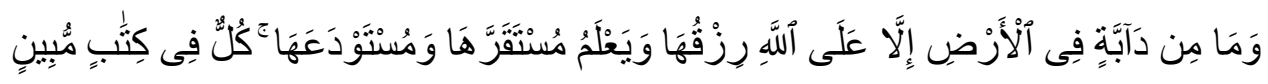

Dan tidak ada suatu binatang melata pun di bumi melainkan Allah-lah yang memberi rezkinya, dan dia mengetahui tempat berdiam binatang itu dan tempat penyimpanannya. semuanya tertulis dalam Kitab yang nyata (Lauh mahfuzh). ${ }^{27}$

Dan ia tidak takut mati,karena kematian dalam keyakinanya adalah sebuah keniscayaan bagi setiap manusia:

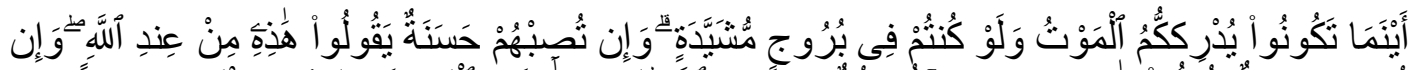

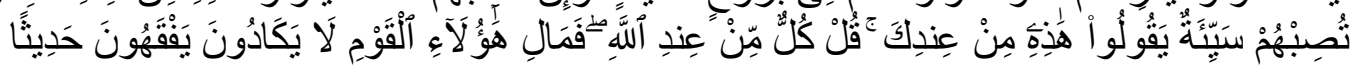

Di mana saja kamu berada, kematian akan mendapatkan kamu, kendatipun kamu di dalam benteng yang Tinggi lagi kokoh. ${ }^{28}$

${ }^{25}$.QS: Al An'am, 82

${ }^{26}$.QS: Adzariyaat, 58.

27 .QS: Hud, 6.

${ }^{28}$.QS: An-Nisa', 78 
Agama diyakini dapat mewujudkan ketenagan jiwa, menghilangkan rasa gelisah, dan ganguan kejiwaan lainya, menambah ketengan hati, dapat mengendalikan perassan ragu, buruk sangka, dan rasa takut. Firman Allah:

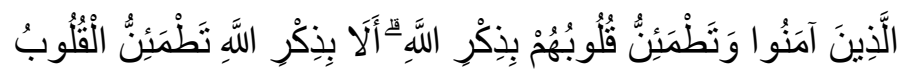

(yaitu) orang-orang yang beriman dan hati mereka manjadi tenteram dengan mengingat Allah. Ingatlah, Hanya dengan mengingati Allah-lah hati menjadi tenteram. ${ }^{29}$

\section{Tinjauan Empiris}

Sejumlah penelitian di beberapa negara, menunjukkan adanya korelasi positif antara menjalankan ajaran agama dan kesehatan mental. Dalam rekomendasinya menyebutkan bahwa melaksanakan ibadah dalam berbagai jenisnya berdampak pada pencegahan ganguan mental dan membawanya pada ketenangan jiwa dan terhindar dari melakukan bunuh diri. Begitu juga hasil analisa kritis terhadap tujuh belas peneltian/research menetapkan: bahwa menghadiri tempat ibadah dan kecendrungan agama internal sangat terkait dengan rendahnya tingkat rasa gelisah, sementara kecendrungan agama simbolis saja berdampak positif pada perasaan gelisah.

Hasil analisa terhadap 49 studi tentang mencontoh praktek beragama, menjelaskan bahwa: contoh positif terhadap praktek beragama mempunyai korelasi dengan penurunan tingkat perasaan sedih, gelisah, dan stress, sementara contoh yang negative terhadap praktek beragama korelasinya kecil dengan kesehatan mental atau dengan keseimbangan jiwa. Hal ini juga lmenunjukkan hasil yang sama antara keyakinan pada agama dan prakteknya dengan orang-orang yang menderita penyakit HIV.

Beberapa hasil penelitian menyimpulkan bahwa sholat dan pujian-pujian dapat memperbaiki kesehatan orang-orang yang sakit hati dan menyembuhkan anak-anak yang menderita penyakit kanker pada darah (Leukemia). Para Psikiater Muslim dengan referensi Islam mampu mengobati dengan cepat orang- orang Islam yang menderita penyakit gelisah dan susah. Dari hasil studi modern menetapkan bahwa sholat mempunyai dampak negative kecil atas orang-orang yang menderita penyakit hati dengan perhatian yang intensif.

Kemudian penelitian trbaru dari 35 studi soal kaitan beragama dan kesehatan mental menetapkan bahwa praktek dalam agama Yahudi dan Kristen serta Agama-agama Timur

${ }^{29}$.QS: Ar Ra'du, 28. 
mempunyai dampak pada penurunan tekanan darah dan membaiknya kerja fungsi tubuh, selain itu Yoga, bersemedi, memiliki kaitan dengan tekanan hormon dan korestol rendah dan kesehatan fisik secara umum. ${ }^{30}$

Berdasarkan pada hasil penelitian dari pakar kedokteran menetapkan: Adanya manfaat besar dalam praktek sholat. Contoh sederhana, sholat dapat mendatangkan kondisi tenang serta menurunkan tensi darah, detak jantung, serta dapat memperkecil hormone yang memyebabkan kolestrol, dan juga berfungsi untuk menambah gelombang alva wasita yang ada pada otak sehingga dapat mengurangi rasa gelisah dan memberi perasaan ridho. Sholat juga berfungsi untuk menambah tingkat proteinya darah (Interlukin 6) yang memperkuat kerja fungsi pencernaan yang bisa dilihat di Lab. ${ }^{31}$

Sebuah studi independent di Amerika menetapkan adanya kebekuan tulang, dan mengecil rata-rata 40\% diantara mereka yang mempelajari buku-buku agama dan mempraktekan syi'arsyi'ar agama, dan para orang tua(Lansia) yang memiliki keimanan yang kuat setelah melakukan operasi sebanyak 14 kali tingkat kematianya lebih kecil dibanding teman-temanya yang tidak memiliki keimanan.

Dari $75 \%$ studi tentang pengaruh agama terhadap kesehatan di Universitas Gortown menyebutkan: Mereka yang hidup dengan keyakinan pada Agama, hidupnya lebih sehat dan dan usianya lebih panjang dibanding dengan orang yang tidak menjadikan agama bagian dari hidupnya, mereka juga lebih cepat disembuhkan dari perasaan susah, dan mereka dapat menjalani operasi dengan sukses.

Dr.Karujuf dari Universitas Doke melakukan studi terapan pada 750 orang yang menderita penyakit kritis di Sembilan pusat pengobatan di beberapa kawasan di Amerika, dan hasilnya menunjukkan orang-orang yang menerima do'a dari orang lain berdampak pada penurunan yang sangant signifikan akan munculnya komplikasi setelah operasi, pada rata-rata $50-100 \%$. Studi lainya menunjukkan bahwa orang-orang yang terkena penyakit HIV yang di do'akan oleh orang lain mereka lebih sedikit mengalami berbagai komplikasi dalam rata-rata sekitar $70 \%{ }^{32}$

\footnotetext{
30 . David R. William and Michelle J Strenthal (Sprituality and religion helath: evidence and research direction) Bioterrorism, Medical Journal of Australia, 2007.

31 . R.F. Gillum and Natalie Dupree (Religiousness, Health, and Health Behavior in Public ) Journal of religion and health, Blanton Peale Institute, 2006.

32 . Kathleen ST. Onge (Bridge to Light, Wayfaring Toward Islam) Publish by the Light, Inc, New York, 2007, pg.134-135.
} 


\section{LANGKAH-LANGKAH MENUJU KESEHATAN MENTAL}

Sehat secara mental adalah pondasi penting untuk menciptakan kepribadian normal. Penyakit mental dibeberapa negara maju menjadi masalah yang mengancam eksistensi masyarakatnya. Kemajuan sains dan tekhnologi oleh manusia seringkali tidak berimbang dengan kemajuan kondisi kejiwaanya. Berikut langkah-langkah meraih kesehatan mental menurut Sayyid Subhi $^{33}$ :

\section{1- Mensucikan jiwa dengan prilaku ikhlas}

Dalam kehidupan manusia seringkali dirundu berbagai cobaan dan ujian. Dari hal tersebut Allah SWT menghendaki untuk mensucikan diri, agar mampu mengemban kesulitan, rela terhadap takdir, sabar menerima cobaan, dan bersyukur ketika lapang. Karena kehendak Allah juga, jiwa manusia senantiasa merasakan suka dan duka, baik dan buruk. Adapun tujuan dari semua cobaan yang terjadi, agar jiwa manusia menjadi bersih dan suci. Ujian Allah tidak pernah pilih kasih pada orang tertentu, negara tertentu, atau agama tertentu pula, akan tetapi hal tersebut tidak bisa dihindari oleh manusia pada umumnya.

Para nabi dan rasul telah menerima menjalani berbagai cobaan dan rintangan, dan hal ini menjadi bagian yang tak terpisah dari hidupnya. Sebagai contoh Nabi Ibrahim dilontarkan kedalam api yang membara, Nabi Yusuf dikhianati oleh saudara-saudaranya sendiri dan harus terpenjara bertahun-tahun, Nabi Isa mendapatkan tekanan dan penyiksaan dari orang-orang Yahudi, sedangkan Nabi Mohammad SAW disiksa, dan dibohongi oleh orang-orang Musyrik, tekanan itu justru muncul dari keluarga terdekatnya seperti Abu Lahab paman rasul sendiri. Semua ujian tidak membuat Rasulullah berhenti berjuang, justru beliau lewati dengan meminta pertolongan Allah, agar dalam setiap kesulitan datang pertolongan. Karena pertolongan Allah Agama Islam tegak diatas bumi. Kemenangan hanya dimiliki oleh hambahamba Allah yang sabar menghadapi ujuan. Firman Allah:

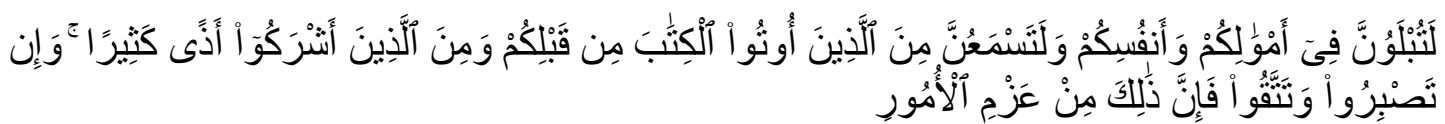

Kamu sungguh-sungguh akan diuji terhadap hartamu dan dirimu. dan (juga) kamu sungguhsungguh akan mendengar dari orang-orang yang diberi Kitab sebelum kamu dan dari orang-

33 . Sayyid Subhi (الانسان وصحته النفسية) Maktabah Usrah, Kairo, 2003, pg. 40-43. 
orang yang mempersekutukan Allah, gangguan yang banyak yang menyakitkan hati. jika kamu bersabar dan bertakwa, Maka Sesungguhnya yang demikian itu termasuk urusan yang patut diutamakan. ${ }^{34}$

\section{2- Memilih jalan moderat (tengah),}

Alqur'an mengajarkan manusia agar meletakkan jiwanya pada posisi yang benar, sehingga tidak menyimpang dari krakter dan dari nilai-nilai yang dimilikinya. Sebagai contoh berdusta dan sombong adalah sifat yang berlawanan dengan krakter jiwa itu sendiri, dan menjaga kesederhanaan dalam hal apapun sebagai krakter utamanya yang harus dipelihara oleh manusia agar terhindar dari segala jenis ganguan atau penyakit kejiwaan.

\section{3- Mencari tauladan yang baik .}

Barometer utama kemulian manusia dalam Islam dilihat dari sejauhmana etikanya dalam berintraksi dengan orang lain. Akhlak dan etika yang baik sebagai indikasi kesucian jiwanya. Allah menempatkan unsur akhlak dalam kepribadian manusia diatas unsur lainya, seperti materi, jabatan, kekuasaan, pengetahuan dll. Rasulullah mulia karena berakhlak mulia:

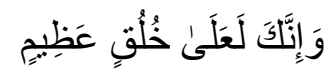

Dan Sesungguhnya kamu benar-benar berbudi pekerti yang agung. ${ }^{35}$

Dalam ayat lain disebutkan:

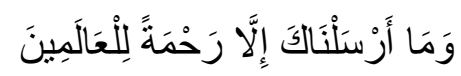

Dan tiadalah kami mengutus kamu, melainkan untuk (menjadi) rahmat bagi semesta alam. ${ }^{36}$

\section{4- Menjaga ketaatan dan menghindar dari kemaksiatan}

Manusia memerlukan banyak belajar supaya dirinya berkeyakinan bahwa, pada setiap kebaiaan bersumber dari niat baik yang kuat, karenanya jiwa manusia harus didorong agar membiasakan berbuat baik, karena kalau tidak demikian akan terdorong pada hal yang negative dan dosa. Allah menjelaskan pentingnya menjaga ketaatan dan menjauhi kemaksiatan:

34 . QS: Ali Imron, 186.

${ }^{35}$.QS: Al Qalam,4.

${ }^{36}$.QS: Al Anbiya', 107. 


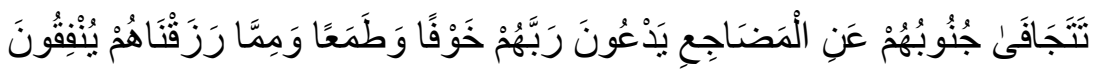

Lambung mereka jauh dari tempat tidurnya dan mereka selalu berdoa kepada Rabbnya dengan penuh rasa takut dan harap, serta mereka menafkahkan apa apa rezki yang kami berikan. ${ }^{37}$

\section{Mendekatkan diri pada yang Maha Pencipta.}

Psikologi modern telah mencapai fase kematanganya setelah munculnya aliran kemanusiaan (Humanistic Aproach) yang mengakui unsur keimanan sebagai satu-satunya jalan dan tujuan yang mengantarkan jiwa pada keselamatan dan ketenangan. Dan hal sulit diwujudkan tanpa adanya adanya korelasi kuat antara manusia dan penciptanya. Firman Allah :

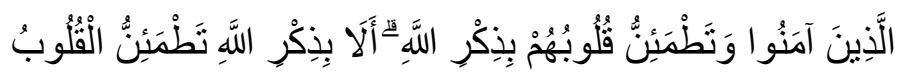

(yaitu) orang-orang yang beriman dan hati mereka manjadi tenteram dengan mengingat Allah. Ingatlah, Hanya dengan mengingati Allah-lah hati menjadi tenteram. ${ }^{38}$

Manusia akan sehat secara mental jika kebutuhan biologisnya telah terpenuhi dengan jalan yang benar, tidak bertentangan dengan hukum Allah. Jika pemenuhan kebutuhanya sesuai dengan aturan syareah, niscaya ia akan merasa tenang dan tentram, namun ketika tidak sesuai akan membuatnya gelisah dan banyak masalah.

\section{PENUTUP}

Masyarakat muslim sebagai model untuk meraih kesehatan mental setidaknya memenuhi tiga faktor penting yaitu: kebutuhan dasarnya terpenuhi dari sumber yang halal, Menjaga hubungan vertikal spritual dan meninggalakn semua laranganya, Membangun hubungan horizontal sosial dengan sebaik mugkin.

Kesimpulanya adalah menunjukkan adanya korelasi kuat antara melakukan ajaran agama baik dalam bentuk ibadah ritual maupun ibadah sosial dengan kesehatan mental, oleh karenya penelitian dalam bidang ini hendaknya terus dilanjutkan pada studi yang lebih dalam, mengingat pentingnya agama dan spritualitas pada masyarakat sekarang, dan studi hal ini perlu disinergikan dengan undang-undang pemeliharan kesehatan.

${ }^{37}$.QS: As sajadah,16.

38 .QS: Ar Ra'du, 28. 


\section{Daftar Pustaka:}

1. Daud Abu (سنن أبو دود) Darul Hadits, Bairut, 1985.

2. Gillum R.F and Natalie Dupree (Religiousness, Health, and Health Behavior in Public) Journal of religion and health, Blanton Peale Institute, 2006.

3. Hadi Abdul (البعد الديني فى الثخصيبة السوية) Maktabah Madbuli, Kairo, 2010.

4. Haisam Mohammad Al Khayyat (فقه الصحة) World Health Organitation Midle East Office, Omman,1984.

5. Kholdun Ibnu (المقدمة) Alhaiat al Misriyyah Lil Kitab, Kairo, 2006.

6. Mohammd Said Abu Hajr Baisuni zaglul (موسو عة ألاطر اف الحديث النبوي الثريق) Darul Kitab Ilmiyah, volume 9, Bairut.

7. Mohammad Abi Abdillah bin Ismail AlBukhori (الجامع الصحيح) Darul Hadits, Suria, 1972,n/j 7239/4.

8. Moammad Abi Isa bin Isa bin Surah (سنن الترميذي) Darul Hadits, Kairo, 2005.

9. Onge Kathleen ST. (Bridge to Light, Wayfaring Toward Islam) Publish by the Light, Inc, New York, 2007.

10. Rozak Abdul Eid (محمد عبذه امام الحذاثة والذستور) kutipan dari Amal Kamilah.

11. Subhi Sayyid (الانسان وصحته النفسية) Maktabah Usrah, Kairo, 2003.

12. Zahron Hamid (الصحة النفسية والعلاج النفسي) Alamul Kitab, Kairo, 2011.

13. William David R. and Michelle J Strenthal (Sprituality and religion helath: evidence and research direction) Bioterrorism, Medical Journal of Australia, 2007. 